\title{
Protein Interactions Investigated by the Raman Spectroscopy for Biosensor Applications
}

\author{
R. P. Kengne-Momo, ${ }^{1,2}$ Ph. Daniel, ${ }^{1}$ F. Lagarde, ${ }^{1}$ Y. L. Jeyachandran, ${ }^{1}$ J. F. Pilard, ${ }^{3}$ \\ M. J. Durand-Thouand, ${ }^{4}$ and G. Thouand ${ }^{4}$ \\ ${ }^{1}$ Laboratoire PEC, UMR CNRS 6087, Université du Maine, A.O. Messiaen, 72085 Le Mans, France \\ ${ }^{2}$ Laboratoire de Chimie Organique, Université de Yaoundé I, B.P 812, Yaoundé, Cameroon \\ ${ }^{3}$ Laboratoire UCO2M, UMR CNRS 6011, Université du Maine, A.O. Messiaen, 72085 Le Mans, France \\ ${ }^{4}$ Laboratoire CBAC, UMR CNRS GEPEA 6144, IUT Université de Nantes, 85035 La Roche Sur Yon, France \\ Correspondence should be addressed to Ph. Daniel, philippe.daniel@univ-lemans.fr
}

Received 24 November 2011; Revised 27 January 2012; Accepted 10 February 2012

Academic Editor: Jaan Laane

Copyright ( $) 2012$ R. P. Kengne-Momo et al. This is an open access article distributed under the Creative Commons Attribution License, which permits unrestricted use, distribution, and reproduction in any medium, provided the original work is properly cited.

Interaction and surface binding characteristics of staphylococcal protein A (SpA) and an anti-Escherichia coli immunoglobulin G (IgG) were studied using the Raman spectroscopy. The tyrosine amino acid residues present in the $\alpha$-helix structure of SpA were found to be involved in interaction with IgG. In bulk interaction condition the native structure of proteins was almost preserved where interaction-related changes were observed in the overall secondary structure ( $\alpha$-helix) of SpA. In the adsorbed state, the protein structure was largely modified, which allowed the identification of tyrosine amino acids involved in SpA and IgG interaction. This study constitutes a direct Raman spectroscopic investigation of SpA and IgG (receptor-antibody) interaction mechanism in the goal of a future biosensor application for detection of pathogenic microorganisms.

\section{Introduction}

Creating protein-protein and protein-surface interactions is the primary step of biological processes in bioimplants, biofouling, immunoassays, and biosensors [1]. Therefore, in the past few years, a great deal for research has been focussed on the understanding of the fundamental structure and physicochemical properties involved in these interactions $[2,3]$, because the applications are strongly connected in the good knowledge of these mechanisms. Structure and orientation changes are often a part of proteins interaction due to various factors such as specific/nonspecific attachment, hydration/dehydration, steric hindrance, competitive adsorption/desorption processes, and experimental conditions $[4,5]$.

However it appears that the protein interactions and their resulting structural conformations are very complicated processes. Facing protein interaction complexity, various analytical tools have been developed to characterize the exhibited different phenomena, physico-chemical behaviors, and interaction structures $[4,6-8]$. Among these tools, the vibrational spectroscopic techniques, such as Raman spectroscopy, are considered as extremely useful tools to chemically and structurally investigate all material compounds, of which protein analysis now constitute a possible and interesting field of applications, more particularly, to determine secondary conformations and interaction structures [9-11]. Actually the Raman scattering technique is a vibrational molecular spectroscopy which, derives from an inelastic light scattering process. With the Raman spectroscopy, a laser photon is scattered by a sample molecule and loses (or gains) energy during the process. The amount of energy lost is seen as a change in energy (wavelength) of the irradiating photon. This energy loss is characteristic for a particular bond in the molecule. The Raman signal is producing a precise spectral sample fingerprint, unique to each atom, group of atoms or individual molecule. In this respect it is similar to the more commonly found FT-IR spectroscopy. However, unlike FTIR, there are a distinct number of advantages when using the Raman: for instance (i) Raman can be used to analyse 
aqueous solutions, (ii) the intensity of spectral features is directly proportional to the concentration of the particular species, (iii) Raman requires little or no sample preparation, and (iv) the use of a Raman microscope provides very high level of spatial resolution and depth discrimination. These advantages and its highly specific nature mean that Raman has become a very powerful tool for analysis and chemical monitoring.

Indeed, the recent technological improvements in Raman spectroscopy, especially in lasers, optics, detectors, and data analysis, make this type of investigation easier. More precisely the sensitivity has increased several orders of magnitude because of advances in optical filters and phonon detectors [12]. For instance single-channel detectors were replaced by CCD detectors whose main advantage is to obtain the spectral information in a single recording. Additionally fluorescence is now minimized by using red/IR excitation in the $630-850 \mathrm{~nm}$ excitation, which became possible by the new photon detectors with high efficiency in this region [13]. Finally problems with interpreting Raman data have been reduced with the avaiability of powerful software which are able to discriminate throughout statistical methods [14]. Raman has the main advantage of being a nondestructive and noninvasive method which will not disturb the studied system, which is a major asset. Finally this optical technique can provide rapid, objective, and reproducible measurements on biological samples. Moreover, the Raman spectroscopy is particularly suitable for detection and analysis of the changes in molecular polarizability of biomolecules, changes involved in the modifications of proteins conformation in binding or interaction mechanisms [9-11, 15, 16]. For instance, the well-resolved amide III band in the Raman spectrum has been used to determine precisely the secondary conformation of protein [17]. The spectral changes associated with aromatic amino acids such as tyrosine, phenylalanine, and tryptophan residues were also used to track some interactions induced by structural modifications $[15,16]$.

SpA and IgG systems were studied because of their importance in affinity biosensor applications. By binding to specific proteins, the fragment crystallizable regions ensure that each antibody generates an appropriate immune response for a given antigen. In the present work, the Raman spectroscopy was used to study the native and interaction structures of a staphylococcal protein $\mathrm{A}(\mathrm{SpA})$ and an immunoglobulin G (IgG) and their complex on pure gold ( $\mathrm{p}-\mathrm{Au})$ and self-assembled monolayer (SAM) functionalized gold (SAM-Au) surfaces. This study is of major importance in the goal of a future bacteria immobilization and detection in the frame of a biosensor design using Raman spectroscopy. Actually one possible biosensing method can be the functionalization of dedicated surfaces in order to specifically detect and fix microorganisms like pathogenic bacteria. The biological elements could be then controlled by a fingerprint technique of which Raman or infrared spectroscopies are possible tools. However, the efficiency of biomolecules detection depends strongly on the success of surface functionalization and on the nature of biomolecules immobilization. The sequence of functionalization includes generally 3 steps: (i) the first step is to functionalize a selected surface (could be gold as in our case) by a chemical way for instance [18], (ii) the second step is bind linker or spacer onto the functionalized polymer surface, and (iii) the final step is then to covalently attach a bioactive compound to the functionalized surface. The second step is actually the more complex one because it includes the fixation of proteins by a covalent way before the immobilization of antibody which is then specific of bioelements that we wish to detect. The full knowledge of protein-antibody interaction is then very important, especially with investigation of the Raman spectroscopy since it is one possible fingerprint technique used in alternative biosensing equipment.

The protein A (SpA) and antibody (IgG) are well known for a long time from a structural point of view, and their interactions were intensively studied as it could be seen in the abundant literature (see for instance the book chapters 19, 20, 21 and some selected examples of articles 22-27). However there are only few Raman spectroscopic investigation published at our knowledge concerning protein A (SpA) and IgG (see for instance [19-22]), and consequently it appears original to understand from a spectroscopic point of view, by a Raman study, the interaction of these both molecules since the potential applications for future biosensors are important.

\section{Experimental Details}

2.1. Materials. Gold films of thickness and surface roughness around $100 \mathrm{~nm}$ and $15 \mathrm{~nm}$, respectively, sputter coated on (100) silicon wafer, were used as substrates. SpA (Cat. no. p6031) purchased from Sigma and an anti-E. coli IgG (Cat. no. GTX40640) purchased from Interchim were used as received without further purification. Sterilised phosphatebuffered saline (PBS) of pH 7.42 was used as protein solvent. Millipore water $(18.2 \mathrm{M} \Omega \cdot \mathrm{cm})$ was used throughout the experiment.

2.2. Substrate Preparation. SAM-Au surfaces were prepared using thiourea and glutaraldehyde. The gold film substrates were first washed in water and ethanol for $20 \mathrm{~min}$ each, cleaned in $1 \%$ aqua regia for $5 \mathrm{~s}$, and rinsed well in water. The cleaned substrates were immerged in $250 \mathrm{mM}$ of aqueous thiourea solution for 24 hours. Then the substrates were activated in 5\% (v/v) of glutaraldehyde in PBS for 20 min. Finally the substrates were rinsed in PBS in order to eliminate nonreacted material and then be used for protein experiments.

As reference surfaces, $\mathrm{p}$-Au surfaces were cleaned in absolute ethanol (Sigma) for $20 \mathrm{~min}$ and washed thoroughly in water before experiments.

2.3. Protein Immobilization. PBS ( $\mathrm{pH} 7.4$ ) was used to prepare $\mathrm{SpA}$ solution and reconstitute the original IgG solution ( $4 \mathrm{mg} / \mathrm{mL}, 0.1 \%$ Sodium Azide, 0.01 M PBS, pH 7.2) in identical concentrations. The final concentrations of both $\mathrm{SpA}$ and IgG solutions were $0.15 \mathrm{mg} / \mathrm{mL}$.

To study the interaction structure of the proteins on SAM-Au surfaces, two distinct experiments were run: (i) in one experiment SpA and IgG were consecutively adsorbed 
(contact presence of 2 hours each); (ii) in the second one, the SpA and IgG solutions were previously mixed (SpA + IgG) in one solution, kept stable for $1 \mathrm{~h}$ at $20^{\circ} \mathrm{C}$, and only then adsorbed on the surface (contact presence $2 \mathrm{~h}$ ). On p-Au surface (reference), SpA and IgG were consecutively adsorbed for an incubation time of $16 \mathrm{~h}$ each.

After adsorption times, all the samples were washed in PBS (10 min.), rinsed in water, and immediately used for Raman measurements. Additionally, the mixed (SpA + IgG) solution was studied in drop coated dry state on $\mathrm{p}$ $\mathrm{Au}$ surface to analyse the bulk protein-protein-interactionrelated structural changes. The Raman spectra were also recorded for the as-received SpA powder and IgG solution ( $4 \mathrm{mg} / \mathrm{ml}$, drop coated in dried state) on $\mathrm{p}$-Au surfaces as reference of their native structure.

2.4. Raman Measurements. Raman spectrometer XploRA (model from Horiba) equipped with a confocal microscope was used. The Raman signals were recorded in a spectral range of $400-3100 \mathrm{~cm}^{-1}$ with an integration time of $300 \mathrm{~s}$ using a $785 \mathrm{~nm}$ red laser excitation, at $10 \mathrm{~mW}$ power, in combination with a $100 \mathrm{x}$ objective magnification (NA $=0.9$ ) of an Olympus BX41 transmission and reflection illumination microscope (Olympus, France) for focus and collection of Raman-scattered light. The confocal hole was set to the minimum value. The dispersive system is comprised of a single grating with 600 groves $/ \mathrm{mm}$, and the Raman signal is collected thanks to a front illuminated CCD detector cooled by thermoelectric Peltier air effect (produced by Horiba, $1024 \times 256$ chip size). A filter rejects the Rayleigh contribution. For each sample, 3 series of independent measurements were carried out and for each set, the Raman experiment was repeated 6 times to check the reproducibility of the measurement and to minimize the possible artifacts and parasitic signals. Each considered spectrum was preprocessed with a 9-point Savitzky-Golay function corresponding to a denoising routine (smoothing filter), background corrected with a polynomial function, and vector normalized using the Labspec software. A more detailed description of spectral acquisition and treatment is presented elsewhere [23].

\section{Results and Discussion}

SpA and IgG are globular proteins with average molecular weights $\sim 42 \mathrm{kDa}$ and $\sim 150 \mathrm{kDa}$, respectively. The secondary conformation of SpA molecules is rich in $\alpha$-helix structure (54\%) and also contains $10-20 \%$ of $\beta$-structure and a large part of coil structure [24]. IgG molecules are predominantly made of $\beta$-sheet (47\%), $7 \%$ of $\alpha$-helices, and remaining, percentage of turns and coils [25]. First of all the reference Raman spectra of both SpA and IgG proteins were recorded; as evidenced in Figure 1, the as-received SpA and IgG proteins clearly revealed their characteristic native secondary conformations. The amide I band around $1659 \mathrm{~cm}^{-1}$ and a relatively higher intense band at $1336 \mathrm{~cm}^{-1}$ in the amide III region were observed in SpA spectrum which are related to its $\alpha$-helix secondary structure characteristics [17]. SpA spectrum also featured a vibration band around

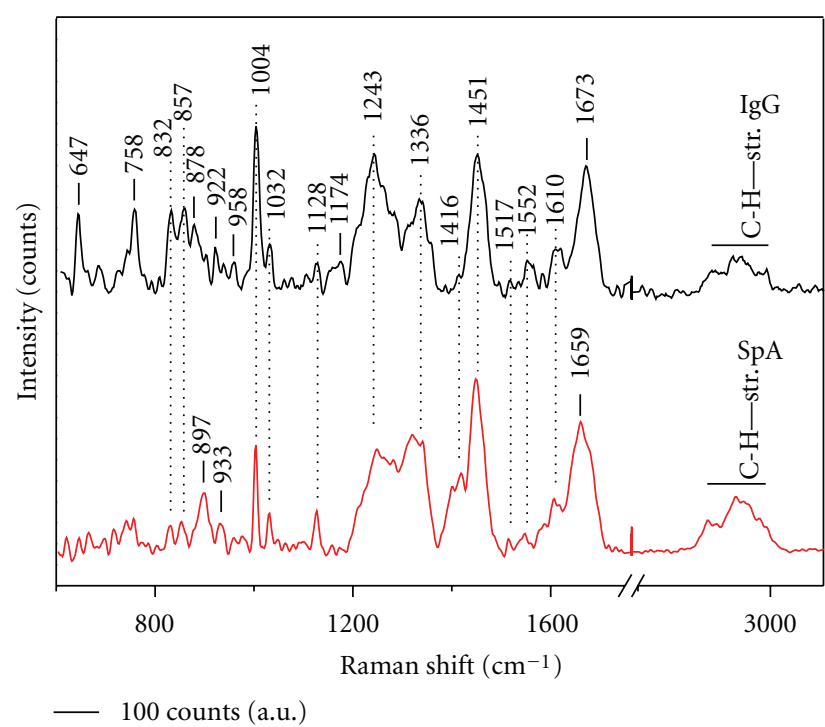

FIgURE 1: The Raman spectra recorded for the as-received SpA and IgG proteins. Conditions of spectra recording: time acquisition $300 \mathrm{~s}$, wavelength $785 \mathrm{~nm}$, nominal power laser $10 \mathrm{~mW}$, optical microscope objective 100x.

$933 \mathrm{~cm}^{-1}$ associated with rocking vibration of $\mathrm{CH}_{3}\left(\delta \mathrm{CH}_{3}\right)$ terminal groups of $\alpha$-helix structure. The predominant $\beta$ sheet structure in IgG was identified by the characteristically amide I band around $1673 \mathrm{~cm}^{-1}$ and a higher intense band at $1243 \mathrm{~cm}^{-1}$ in the amide III region [17]. The other vibration bands generally associated with protein structures are assigned as follows from the literature [26]. The $\mathrm{C}-\mathrm{H}$ stretching $(\nu \mathrm{C}-\mathrm{H})$ vibration bands of aliphatic side-chains were observed around $2860 \mathrm{~cm}^{-1}$ to $2940 \mathrm{~cm}^{-1}$. The $\mathrm{CH}_{2}$ deformation $\left(\rho \mathrm{CH}_{2}\right)$ band was observed around $1451 \mathrm{~cm}^{-1}$. Vibration bands associated with phenylalanine amino acid residue were observed around $1610 \mathrm{~cm}^{-1}$ and $1004 \mathrm{~cm}^{-1}$. The bands associated with tyrosine were observed around $857 \mathrm{~cm}^{-1}$ (buried), $832 \mathrm{~cm}^{-1}$ (exposed), $758 \mathrm{~cm}^{-1}$, and $647 \mathrm{~cm}^{-1}$ (skeletal). Tryptophan (indole rings) residue bands were observed around $1552 \mathrm{~cm}^{-1}$ and $1416 \mathrm{~cm}^{-1}$. The bands in the region $920 \mathrm{~cm}^{-1}$ to $880 \mathrm{~cm}^{-1}$ could be assigned to $\rho \mathrm{CH}_{2}$ and the ones around $958 \mathrm{~cm}^{-1}$ to $\rho \mathrm{CH}_{3}$ vibrations. Backbone skeletal $v \mathrm{C}-\mathrm{C}$ vibration bands were also observed in the region of $1170 \mathrm{~cm}^{-1}$ to $1032 \mathrm{~cm}^{-1}$. Table 1 summarizes the suggested assignment.

The Raman spectrum measured for the drop coated layer of previously mixed SpA + IgG solution $(0.15 \mathrm{mg} / \mathrm{mL})$ on $\mathrm{p}$ Au surface is shown in Figure 2. Interesting and new spectral features, assumed to be produced by SpA-IgG interaction, were observed. The amide I band was observed around $1672 \mathrm{~cm}^{-1}$ corresponding to the $\beta$-sheet structure, characteristically considered coming from IgG. However, the amide III region $\left(1240 \mathrm{~cm}^{-1}\right.$ to $\left.1350 \mathrm{~cm}^{-1}\right)$ showed characteristics of $\alpha$-helix structure with a relatively higher intensity band around $1338 \mathrm{~cm}^{-1}$ associated with bending $\delta \mathrm{C}_{\alpha}-\mathrm{H}$ vibration in main-chain of $\alpha$-helix. Moreover, the band at $932 \mathrm{~cm}^{-1}$ associated with $\alpha$-helix $\mathrm{CH}_{3}$ groups increased in intensity compared with the reference SpA spectrum (see Figure 1). 
TABLE 1: Interpretation of the reference Raman spectra of proteins $\mathrm{SpA}$ and IgG. The bands characteristics of SpA or IgG, respectively, are indicated in bold letters for characterization of the intensity level: vw: very weak, w: weak, m: medium, s: strong, vs: very strong.

\begin{tabular}{lccc}
\hline Frequency $\left(\mathrm{cm}^{-1}\right)$ & Compound & Assignment & Intensity \\
\hline 647 & SpA/IgG & Tyrosine & $\mathrm{vw} / \mathrm{m}$ \\
758 & SpA/IgG & Tyrosine & $\mathrm{vw} / \mathrm{m}$ \\
832 & SpA/IgG & Tyrosine & $\mathrm{w} / \mathrm{m}$ \\
857 & SpA/IgG & Tyrosine & $\mathrm{w} / \mathrm{m}$ \\
$880-920$ & SpA/IgG & $\rho \mathrm{CH}_{2}$ & $\mathrm{~m} / \mathrm{m}$ \\
$\mathbf{9 3 3}$ & SpA & $\delta \mathbf{C H}_{3}$ & $\mathbf{w}$ \\
958 & SpA/IgG & $\rho \mathrm{CH}_{3}$ & $\mathrm{w} / \mathrm{w}$ \\
1004 & SpA/IgG & Phenylalanine & $\mathrm{s} / \mathrm{vs}$ \\
$1032-1170$ & SpA/IgG & $\nu$ C-C or alkyl C-N & $\mathrm{w} / \mathrm{w}$ \\
$\mathbf{1 2 4 3}$ & IgG & Amide III & vs \\
1336 & SpA & Amide III & vs \\
1416 & SpA/IgG & Tryptophan & $\mathrm{s} / \mathrm{vs}$ \\
1451 & SpA/IgG & $\rho \mathrm{CH}$ & $\mathrm{vs} / \mathrm{vs}$ \\
1552 & SpA/IgG & Tryptophan & $\mathrm{w} / \mathrm{w}$ \\
1610 & SpA/IgG & Phenylalanine & $\mathrm{m} / \mathrm{m}$ \\
1659 & SpA & Amide I & vs \\
1673 & IgG & Amide I & vs \\
2860 & SpA/IgG & $\nu \mathrm{C}-\mathrm{H}$ & $\mathrm{m} / \mathrm{w}$ \\
2940 & SpA/IgG & $\nu \mathrm{C}-\mathrm{H}$ & $\mathrm{m} / \mathrm{w}$ \\
\hline
\end{tabular}

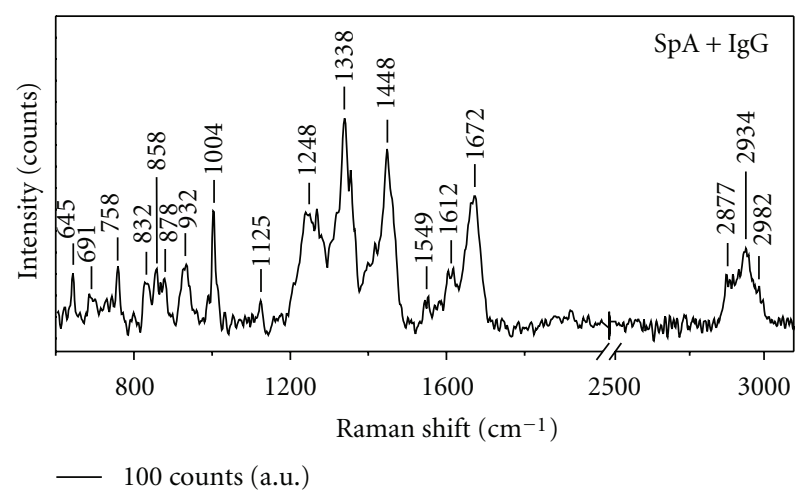

FIgURE 2: The Raman spectra of drop-coated SpA + IgG mixture in dry state. Conditions of spectra recording: time acquisition $300 \mathrm{~s}$, wavelength $785 \mathrm{~nm}$, nominal power laser $10 \mathrm{~mW}$, optical microscope objective $100 x$.

These observations show that the $\alpha$-helix main-chain of SpA is predominantly involved in interaction with IgG. The other vibration bands observed in SpA-IgG interacting spectrum correspond to the bands observed in native SpA and IgG spectra (see Figure 1) with small shifts. These shifts can be attributed to the modification of the local structure of each entity due to the interaction. Note that the stretching band around $1032 \mathrm{~cm}^{-1}$ associated with cis conformation of skeletal $\nu \mathrm{C}-\mathrm{C}$ that is identified in the native spectra was not observed after interaction.

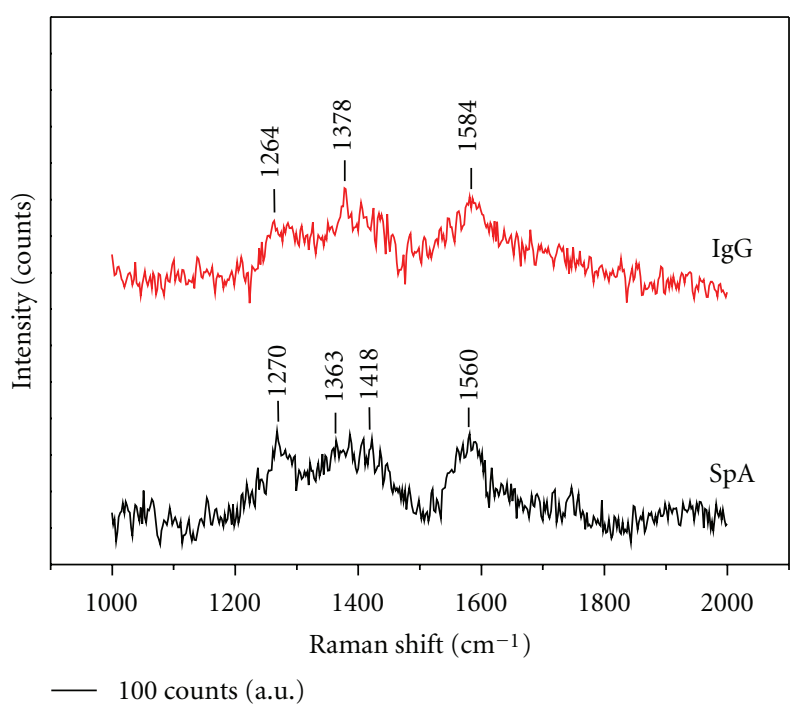

Figure 3: The Raman spectra of drop-coated SpA + IgG mixture in dry state. Conditions of spectra recording: time acquisition $300 \mathrm{~s}$, wavelength $785 \mathrm{~nm}$, nominal power laser $10 \mathrm{~mW}$, optical microscope objective 100x.

As introduced, our main goal is the study of the proteinsurface interaction by adsorbing the proteins in $\mathrm{p}-\mathrm{Au}$ and also SAM-Au surfaces. The Raman spectra of SpA and IgG consecutively adsorbed on p-Au surface are shown in Figure 3. Adsorption of SpA and IgG on p-Au surface was found to be very low to produce any significant spectral features other than the overlapped broad vibration bands in the region of amide (I and III) and aliphatic sidechain groups. However note that it is not possible to avoid conformational changes to the native structure that may be induced by studying the proteins on the $\mathrm{p}$-Au surface.

On the contrary, SAM-Au surfaces showed strong binding with proteins. Additionally the results are evidently more pertinent because the SAM layer has the potential to protect the proteins from interacting with and denaturing on the Au surface. Figure 4(a) shows the Raman spectra of $\mathrm{SpA}$ and IgG proteins consecutively adsorbed on SAM-Au surface, and Figure 4(b) shows the spectrum of molecules adsorbed from SpA + IgG interacting solution on SAM$\mathrm{Au}$ surface. Despite the incubation time of $2 \mathrm{~h}$, strong and well-resolved Raman signals from proteins were identified. The protein molecules adsorbed on SAM-Au surfaces were found to be largely modified in amide main chain and aliphatic side-chain structure as compared to their native structure due to strong surface binding. The proposed Raman assignments are then done in the next part according to the reference assignment shown in Table 1 . However, the Raman signals associated with amino acid residues such as tyrosine $\left(637-800 \mathrm{~cm}^{-1}\right)$ and phenylalanine were found to be enhanced. The Raman spectra of Figure 4 featured some of the common vibration bands of proteins such as amide I around $1656 \mathrm{~cm}^{-1}$ and $1633 \mathrm{~cm}^{-1}$, aliphatic side chains from $1420 \mathrm{~cm}^{-1}$ to $1466 \mathrm{~cm}^{-1}$, amide III from $1311 \mathrm{~cm}^{-1}$ to $1278 \mathrm{~cm}^{-1}$, and alkyl C-N or skeletal $\nu \mathrm{C}-\mathrm{C}$ between 


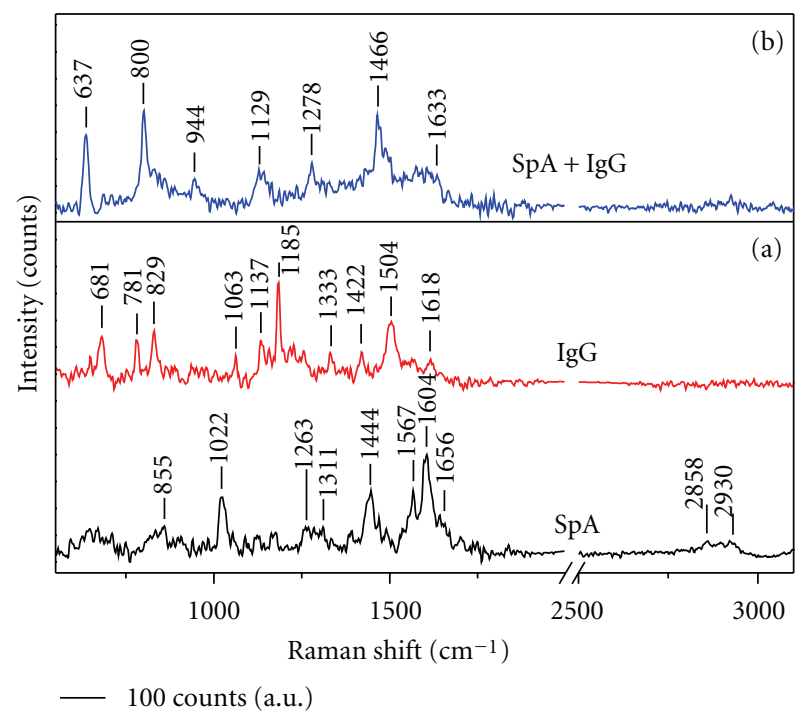

FIgURE 4: The Raman spectra of (a) consecutively adsorbed SpA and IgG on SAM-Au surface and (b) SpA + IgG interacting molecules adsorbed from SpA and IgG mixed solution on SAMAu surface. Conditions of spectra recording: time acquisition $300 \mathrm{~s}$, wavelength $785 \mathrm{~nm}$, nominal power laser $10 \mathrm{~mW}$, optical microscope objective 100x.

$1130 \mathrm{~cm}^{-1}$ and $1050 \mathrm{~cm}^{-1}$. The spectra also featured some enhancement in band intensity or new bands produced due to strong surface binding of proteins with SAM-Au.

The Raman bands observed in the SpA spectrum (Figure 4(a)) around $1604 \mathrm{~cm}^{-1}, 1567 \mathrm{~cm}^{-1}$, and $855 \mathrm{~cm}^{-1}$ could be assigned to phenylalanine, tryptophan, and tyrosine amino acid residues, respectively. The spectrum of adsorbed IgG (Figure 4(a)) on SpA adsorbed SAM-Au layer featured most of the Raman signals associated with tyrosine amino acid residue. The bands observed around $1618 \mathrm{~cm}^{-1}$, $1504 \mathrm{~cm}^{-1}, 829 \mathrm{~cm}^{-1}, 781 \mathrm{~cm}^{-1}$, and $681 \mathrm{~cm}^{-1}$ could be associated to tyrosine residue. However the origin of an intense band at $1185 \mathrm{~cm}^{-1}$ in the IgG spectrum is not clear. This signal may be produced from $\delta \mathrm{CCH}$ vibration in IgG or from the conjugated biotin molecule. In Figure 4(b), the spectrum of ( $\mathrm{SpA}+\mathrm{IgG})$ solution also showed strong Raman signals associated with tyrosine residue around $800 \mathrm{~cm}^{-1}$ and $637 \mathrm{~cm}^{-1}$ with a shift and a small signal around $944 \mathrm{~cm}^{-1}$ associated with $\mathrm{CH}_{3}$ groups in $\alpha$-helix. An important observation from the IgG and SpA + IgG spectra is the predominant presence of tyrosine bands. Tyrosine residues are known to be involved in receptor (SpA)-antibody (IgG) binding [27]. Our observation is a spectroscopic evidence for the involvement of tyrosine residue in SpA-IgG binding at adsorbed state. However, in the bulk state binding of SpA and IgG (Figure 2), the involvement of tyrosine was not clearly revealed, but changes in $\alpha$-helix main chain of SpA were observed. These two different kinds of information explain that the SpA and IgG binding is mediated by tyrosine amino acid residues present in the $\alpha$-helix main chain of SpA molecule. This may be one of the important reasons that make SpA a good receptor molecule for IgG binding in affinity biosensors.

Considering the enhancement of some bands (tyrosine and phenylalanine), one open question could be suggested: why are these bands enhanced because a classical dispersive Raman spectroscopy was used in this work? Actually, even if the process is not well understood, the $\mathrm{Au}$ substrate could increase the Raman signal of SAMs and the molecules adsorbed on it if the Au surface is constituted of nanometersscale domains [28], which is the case here. It means that we can suggest that this enhancement is not probably due to denaturation of the surface.

The Raman signal enhancement is a mechanism which can be usually observed in SERS method which generally associate silver or gold colloids or rough metal surfaces to investigated molecules. Considering metal nanoclusters (e.g., gold or silver nanoparticles), they provide a strong enhancement of the Raman signals of molecules attached to them (see for instance [29-31]). In particular, gold nanoparticles may significantly reduce the adsorption of molecules with fluorescent backgrounds when they are used as Raman substrates. It has been shown that SERS detection method with gold nanoparticles probes generally greatly increase specificity and detection. Specific recognition of proteins by conjugates of gold nanoparticles and antibodies followed by an enhancement step based on the electroless deposition of silver onto the gold particles has been employed for protein identification in histochemistry using dot and blot assays [32, 33]. Using the same detection principle, a nanoparticle-based Raman spectroscopic encoding approach for DNA, RNA, or protein detection was developed (see for instance [34]) some years ago. Then the SERS method is clearly a good process for the Raman protein signal increasing. The SERS method does not need any additional Raman equipment but, if the enhancement can be very strong (up to a $10^{6}$ factor), it can be strongly dependent on the aggregations of the particles $[35,36]$ and then gives selective enhancement of bands. We suppose that this phenomenon could explain and could be connected to our results of specific bands enhancements.

\section{Conclusions}

The native structure and interaction structure in bulk and adsorbed state of SpA and an IgG were studied by the Raman spectroscopy. SpA and IgG interaction in bulk state showed significant structural changes in the $\alpha$-helix secondary structure of SpA; however, the adsorbed state on SAM-Au surfaces clearly revealed the involvement of tyrosine amino acid residues in the interaction mechanism. It is concluded that the tyrosine residues present in the $\alpha$ helix of SpA mediate the interaction with $\operatorname{IgG}$, and this characteristic makes SpA a unique receptor molecule for IgG in biosensors applications. Furthermore, the different tyrosine bands observed in the adsorbed state spectra of proteins are associated with different forms of tyrosine such as buried, exposed, free, and skeletal. This information could be used for advance understanding of SpA-IgG binding on 
surfaces. This work will be very useful considering the potential applications in biosensors for detection of pathogens. Actually one possible alternative way for the detection of pathogenic bacteria is to imagine a specific functionalized surface (SAM-Au surface for instance) which will be able to fix microorganisms and could be detected by spectroscopy. However the understanding of this SpA-IgG interaction mechanism appears to be very important previously to any fixation of biological element.

\section{Acknowledgments}

The present work was supported by the Grant RMBBIORAM booked by the Région Pays de la Loire, Le Conseil Général de la Vendée, La Ville de la Roche sur Yon.

\section{References}

[1] R. A. Latour Jr., "Protein-surface interactions," in Biomaterials: Protein-Surface Interactions: Encyclopedia of Biomaterials and Biomedical Engineering, G. E. Wnek and G. L. Bowlin, Eds., pp. 270-284, Informa Healthcare, New York, NY, USA, 2008.

[2] I. S. Moreira, P. A. Fernandes, and M. J. Ramos, "Hot spotsa review of the protein-protein interface determinant aminoacid residues," Proteins, vol. 68, no. 4, pp. 803-812, 2007.

[3] J. A. Mielczarski, J. Dong, and E. Mielczarski, "Real time evaluation of composition and structure of concanavalin a adsorbed on a polystyrene surface," Journal of Physical Chemistry B, vol. 112, no. 16, pp. 5228-5237, 2008.

[4] Y. L. Jeyachandran, E. Mielczarski, B. Rai, and J. A. Mielczarski, "Quantitative and qualitative evaluation of adsorption/desorption of bovine serum albumin on hydrophilic and hydrophobic surfaces," Langmuir, vol. 25, no. 19, pp. 1161411620, 2009.

[5] M. Rankl, T. Ruckstuhl, M. Rabe, G. R. J. Artus, A. Walser, and S. Seeger, "Conformational reorientation of immunoglobulin $\mathrm{G}$ during nonspecific interaction with surfaces," ChemPhysChem, vol. 7, no. 4, pp. 837-846, 2006.

[6] J. Pande, C. Pande, D. Gilg, M. Vašák, R. Callender, and J. H. R. Kägi, "Raman, infrared, and circular dichroism spectroscopic studies on metallothionein: a predominantly "turn"-containing protein," Biochemistry, vol. 25, no. 19, pp. 5526-5532, 1986.

[7] Z. Q. Wen, L. Hecht, and L. D. Barron, “ $\beta$-Sheet and associated turn signatures in vibrational Raman optical activity spectra of proteins," Protein Science, vol. 3, no. 3, pp. 435-439, 1994.

[8] M. Malmsten, "Ellipsometry studies of fibronectin adsorption," Colloids and Surfaces B, vol. 3, no. 6, pp. 371-381, 1995.

[9] G. J. Thomas Jr., "New structural insights from Raman spectroscopy of proteins and their assemblies," Biopolymers, vol. 67 , no. $4-5$, pp. 214-225, 2002.

[10] R. Tuma, "Raman spectroscopy of proteins: from peptides to large assemblies," Journal of Raman Spectroscopy, vol. 36, no. 4, pp. 307-319, 2005.

[11] J. Filik and N. Stone, "Drop coating deposition Raman spectroscopy of protein mixtures," Analyst, vol. 132, no. 6, pp. 544-550, 2007.

[12] X. Peng, J. Jonas, and J. L. Silva, "Molten-globule conformation of Arc repressor monomers determined by high- pressure $1 \mathrm{H}$ NMR spectroscopy," Proceedings of the National Academy of Sciences of the United States of America, vol. 90, no. 5, pp. 1776-1780, 1993.
[13] J. Dong, D. Dinakarpandian, and P. R. Carey, "Extending the raman analysis of biological samples to the 100 micromolar concentration range," Applied Spectroscopy, vol. 52, no. 8, pp. 1117-1122, 1998.

[14] R. Goodacre, E. M. Timmins, R. Burton et al., "Rapid identification of urinary tract infection bacteria using hyperspectral whole-organism fingerprinting and artificial neural networks," Microbiology, vol. 144, no. 5, pp. 1157-1170, 1998.

[15] A. M. Ahern and R. L. Garrell, "Protein-metal interactions in protein-colloid conjugates probed by surface-enhanced raman spectroscopy," Langmuir, vol. 7, no. 2, pp. 254-261, 1991.

[16] S. F. El-Mashtoly, S. Yamauchi, M. Kumauchi, N. Hamada, F. Tokunaga, and M. Unno, "Structural changes during the photocycle of photoactive yellow protein monitored by ultraviolet resonance Raman spectra of tyrosine and tryptophan," Journal of Physical Chemistry B, vol. 109, no. 49, pp. 23666-23673, 2005.

[17] S. Cai and B. R. Singh, "A distinct utility of the amide III infrared band for secondary structure estimation of aqueous protein solutions using partial least squares methods," Biochemistry, vol. 43, no. 9, pp. 2541-2549, 2004.

[18] R. P. Kengne-Momo, Y. L. Jeyachandran, A. Assaf et al., "A simple method of surface functionalisation for immunospecific immobilisation of proteins," Analytical and Bioanalytical Chemistry, vol. 398, no. 3, pp. 1249-1255, 2010.

[19] Z. A. Combs, S. Chang, T. Clark, S. Singamaneni, K. D. Anderson, and V. V. Tsukruk, "Label-free raman mapping of surface distribution of protein A and IgG biomolecules," Langmuir, vol. 27, no. 6, pp. 3198-3205, 2011.

[20] J. Duarte, M. T. Pacheco, R. Z. Machado, L. Silveira, R. A. Zangaro, and A. B. Villaverd, "Use of near-infrared raman spectroscopy to detect IgG and IgM antibodies against Toxoplasma gondii in serum samples of domestic cats," Cellular and Molecular Biology, vol. 48, no. 5, pp. 585-589, 2002.

[21] R. Kumar, M. M. Bajaj, and B. Swaroop, "Conformational changes in the IgG molecule of lepromatous sera using laser Raman spectroscopy," Indian Journal of Leprosy, vol. 60, no. 3, pp. 363-373, 1988.

[22] P. C. Painter and L. E. Mosher, "The low-frequency Raman spectrum of an antibody molecule: bovine IgG," Biopolymers, vol. 18, no. 12, pp. 3121-3123, 1979.

[23] P. Daniel, P. Picart, L. Bendriaa et al., "Effects of toxic organotin compounds on bacteria investigated by microRaman spectroscopy," Spectroscopy Letters, vol. 41, no. 1, pp. 19-28, 2008.

[24] I. Sjoholm, "Protein A from Staphylococcus aureus. Spectropolarimetric and spectrophotometric studies," European Journal of Biochemistry, vol. 51, no. 1, pp. 55-61, 1975.

[25] M. Marquart, J. Deisenhofer, and R. Huber, "Crystallographic refinement and atomic models of the intact immunoglobulin molecule Kol and its antigen-binding fragment at $3.0 \theta$ and 1.9 $\theta$ resolution," Journal of Molecular Biology, vol. 141, no. 4, pp. 369-391, 1980.

[26] D. Naumann, "Ft-infrared and Ft-raman spectroscopy in biomedical research," Applied Spectroscopy Reviews, vol. 36, no. 2-3, pp. 239-298, 2001.

[27] G. C. Stone, U. Sjobring, L. Bjorck, J. Sjoquist, C. V. Barber, and F. A. Nardella, "The Fc binding site for streptococcal protein $\mathrm{G}$ is in the $\mathrm{C} \gamma 2-\mathrm{C} \gamma 3$ interface region of $\mathrm{IgG}$ and is related to the sites that bind staphylococcal protein $\mathrm{A}$ and human rheumatoid factors," Journal of Immunology, vol. 143, no. 2, pp. 565-570, 1989.

[28] T. Wadayama and M. Oishi, "Surface-enhanced Raman spectral study of Au nano-particles/alkanethiol self-assembled 
monolayers/Au( 1111 ) heterostructures," Surface Science, vol. 600, no. 18, pp. 4352-4356, 2006.

[29] S. Nie and S. R. Emory, "Probing single molecules and single nanoparticles by surface-enhanced Raman scattering," Science, vol. 275, no. 5303, pp. 1102-1106, 1997.

[30] R. A. Reynolds III, C. A. Mirkin, and R. L. Letsinger, "Homogeneous, nanoparticle-based quantitative colorimetric detection of oligonucleotides," Journal of the American Chemical Society, vol. 122, no. 15, pp. 3795-3796, 2000.

[31] T. A. Taton, G. Lu, and C. A. Mirkin, "Two-color labeling of oligonucleotide arrays via size-selective scattering of nanoparticle probes," Journal of the American Chemical Society, vol. 123, no. 21, pp. 5164-5165, 2001.

[32] C. S. Holgate, P. Jackson, P. N. Cowen, and C. C. Bird, "Immunogold-silver staining: new method of immunostaining with enhanced sensitivity," Journal of Histochemistry and Cytochemistry, vol. 31, no. 7, pp. 938-944, 1983.

[33] M. Moeremans, G. Daneels, and A. Van Dijck, "Sensitive visualization of antigen-antibody reactions in dot and blot immune overlay assays with immunogold and immunogold/silver staining," Journal of Immunological Methods, vol. 74, no. 2, pp. 353-360, 1984.

[34] Y. C. Cao, R. Jin, and C. A. Mirkin, "Nanoparticles with Raman spectroscopic fingerprints for DNA and RNA detection," Science, vol. 297, no. 5586, pp. 1536-1540, 2002.

[35] S. Sánchez-Cortés, J. V. García-Ramos, G. Morcillo, and A. Tinti, "Morphological study of silver colloids employed in surface-enhanced raman spectroscopy: activation when exciting in visible and near-infrared regions," Journal of Colloid And Interface Science, vol. 175, no. 2, pp. 358-368, 1995.

[36] J. Neng, M. H. Harpster, H. Zhang, J. O. Mecham, W. C. Wilson, and P. A. Johnson, "A versatile SERS-based immunoassay for immunoglobulin detection using antigencoated gold nanoparticles and malachite green-conjugated protein A/G," Biosensors and Bioelectronics, vol. 26, no. 3, pp. 1009-1015, 2010. 


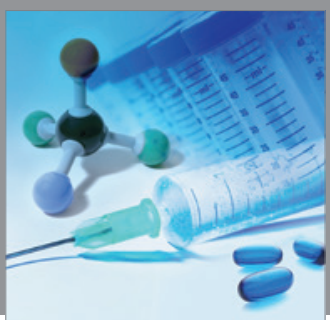

International Journal of

Medicinal Chemistry

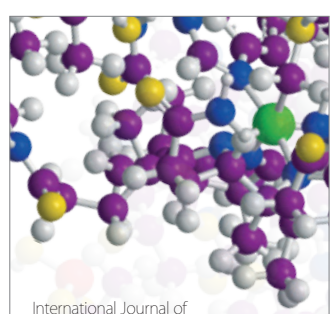

Carbohydrate Chemistry

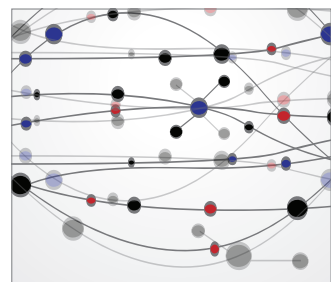

The Scientific World Journal
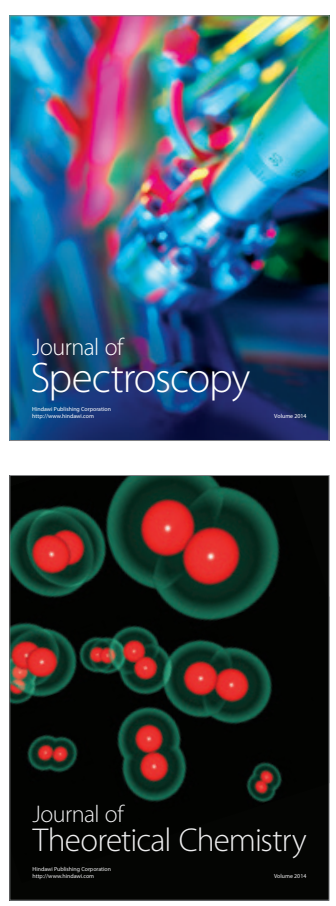
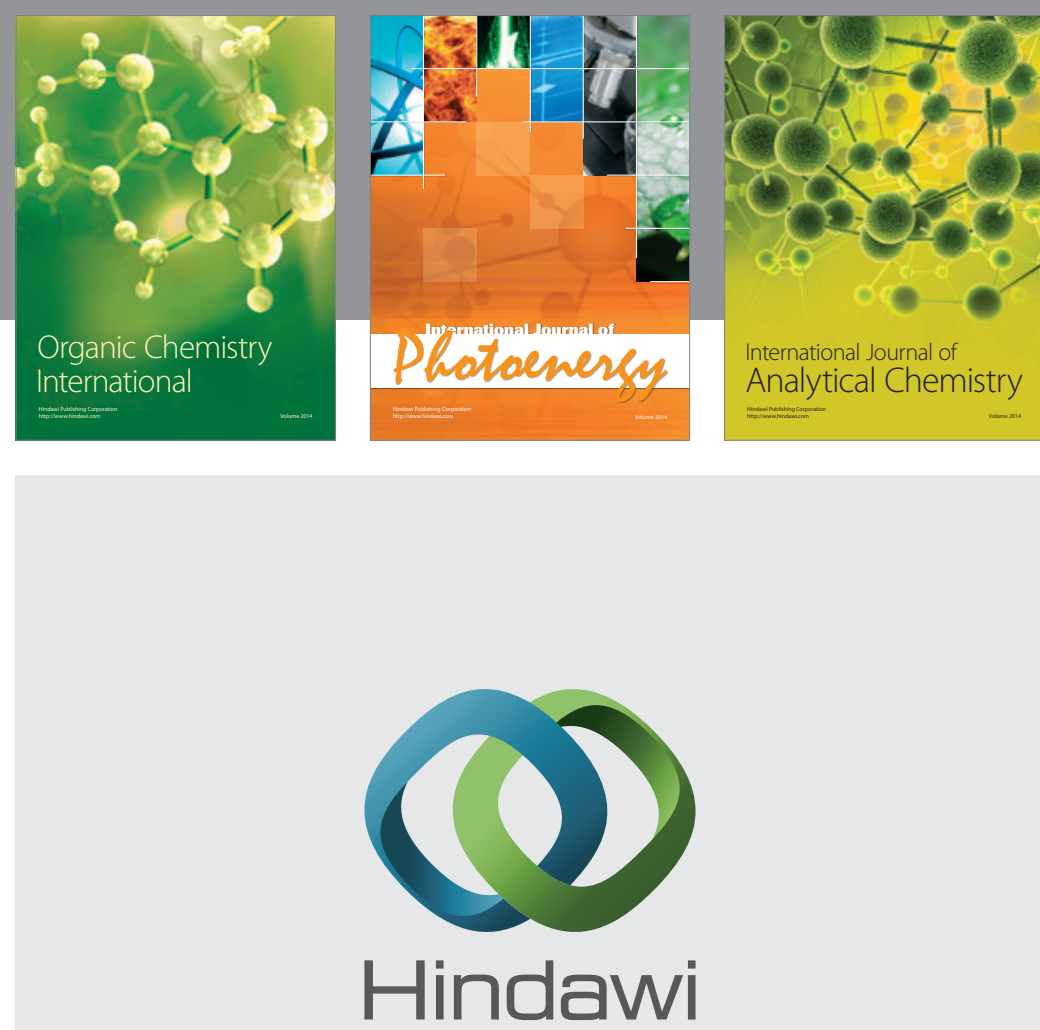

Submit your manuscripts at

http://www.hindawi.com
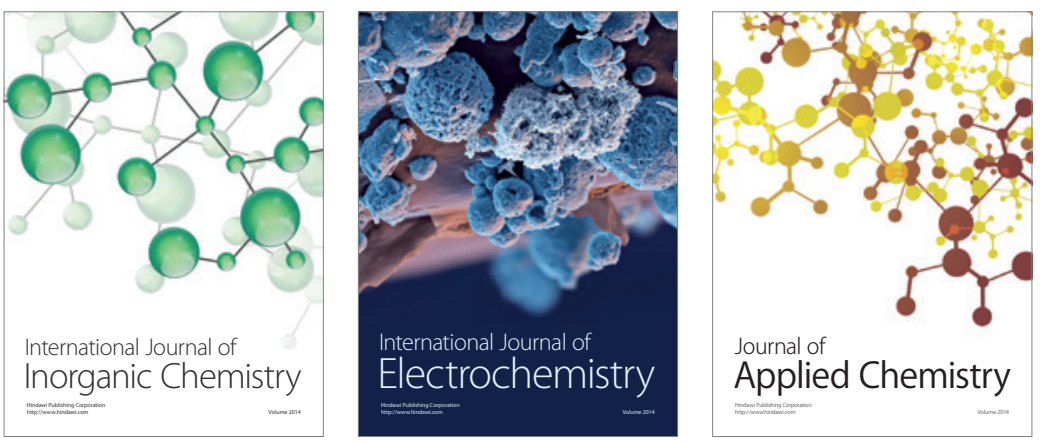

Journal of

Applied Chemistry
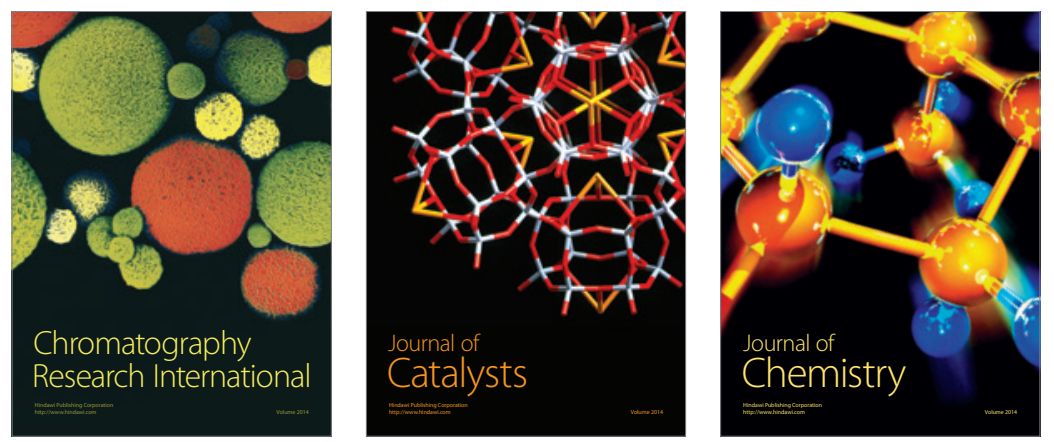
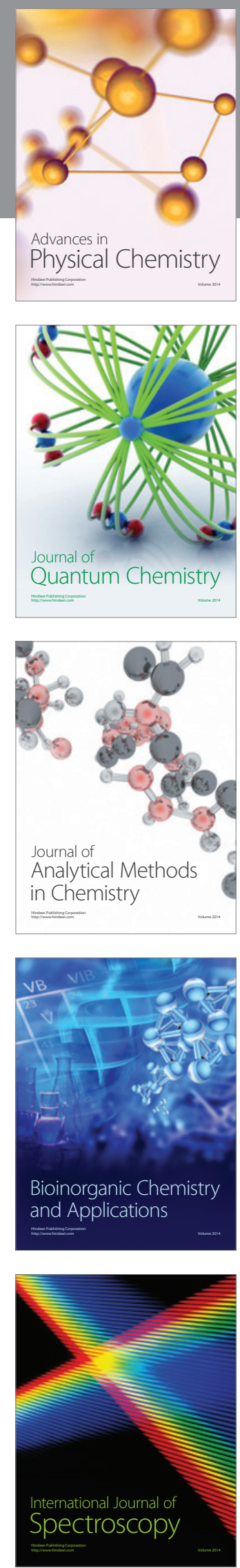